\title{
Pattern of bacterial isolates in the middle ear discharge of patients with chronic suppurative otitis media in a tertiary hospital in North central Nigeria
}

\author{
*Afolabi $\mathrm{OA}^{1}$, Salaudeen $\mathrm{AG}^{2}$, Ologe $\mathrm{FE}^{1}$, Nwabuisi $\mathrm{C}^{3}$, Nwawolo $\mathrm{CC}^{4}$ \\ 1. Department of Ear, Nose and Throat surgery, University of Ilorin, Ilorin, Nigeria \\ 2. Department of Epidemiology and Community Health, University of Ilorin Teaching Hospital, Ilorin, Nigeria \\ 3. Department of Microbiology, University of Ilorin Teaching Hospital, Ilorin, Nigeria \\ 4. Ear, Nose and Throat Surgery Unit, Department of Surgery, University of Lagos
}

\begin{abstract}
Background: Otitis media (OM) is a major health problem in both developed and developing countries.

Objective: To determine the pattern of bacterial isolates in patients with chronic suppurative otitis media(CSOM) in Ilorin, Nigeria.

Methods: A prospective study carried out in University of Ilorin Teaching Hospital, Nigeria among consenting patients with CSOM attending the ENT clinic over a period of 7 months. Informed consent was obtained from the patients or caregivers and approval for the study obtained from ethical committee. Structured questionnaire was administered and microbiological analysis done, data obtained was entered into SPSS statistical software and results presented in tables and figures.

Results: A total of 134 patients aged 5-64yrs with chronic suppurative otitis media were interviewed with a mean age of 17.0 (S.D. $=15.1 \pm 1.30)$. About $55.2 \%$ of the respondents were under $10 y r s$. Seventy-two $(53.7 \%)$ of the respondents were males with $\mathrm{M}: \mathrm{F}=1.2: 1$. The gram stain showed predominantly gram negative organisms (71.6\%). Pseudomonas aeruginosa was the commonest middle ear pathogenic organism identified and the sensitivity pattern highly favoured ciprofloxacin Conclusion: CSOM is still a childhood problem among the under tens' more prevalent among males and the commonest agent is Pseudomonas aeruginosa. Ciprofloxacin is still the most sensitive antibiotics in vitro.
\end{abstract}

Keywords: Otitis media, chronic, Bacterial isolates, antibiotics

African Health Sciences 2012; 12(3): 362 - 368 http://dx.doi.org/10.4314/ahs.v12i3.18

\section{Introduction}

Otitis media $(\mathrm{OM})$ is a major health problem and occurs with a high incidence and prevalence in both developed and developing countries ${ }^{1,2}$. It may be acute, chronic or recurrent. It can be suppurative or non-suppurative: Acute suppurative otitis media (ASOM) is a common childhood illness and can progress to chronic supportive otitis media (CSOM) ${ }^{3}$. Chronic suppurative otitis media (CSOM) is defined as a disease condition of the middle ear cleft (Eustachian tube, tympanic cavity and mastoid air cells) characterized by the presence of persistent perforation of the tympanic membrane with recurrent or persistent mucoid or muco-purulent discharge for at least eight (8) weeks ${ }^{4-7}$.

*Correspondence author:
Afolabi Olushola Abdulrahman
Department of Ear, Nose and Throat Surgery
University of Ilorin
Ilorin, Nigeria
Tel +2348035727069
Email: $\underline{\text { droaafolabi@yahoo.com }}$

Studies in United States, United Kingdom, Japan, India, Ghana, Sierra-Leone and Nigeria revealed some group of organisms that have been recorded in CSOM. The common causative organism may be aerobic (e.g. Pseudomonas aeruginosa, Escherichia coli, Staphylococcus. aureus, Streptococcus pyogenes, Proteus mirabilis, Klebsiella species) or anaerobic (e.g. Bacteroides, Peptostreptococcus, Proprionibacterium $)^{4,6,7,9}$ or mixed organisms. The disease may begin in childhood ${ }^{10}$ or as a complication of untreated or inadequately treated acute suppurative otitis media ${ }^{11}$ or may be chronic from onset ${ }^{12}$. The bacteria may gain entry to the middle ear through a chronic perforation ${ }^{13}$. Children tend to have higher predisposition to ear infection than adults because anatomy of the eustachian tube in children permits easier access of organism through the nasopharynx ${ }^{14}$.

The aim of the study is to determine the pattern of bacterial isolates in patients with chronic suppurative otitis media in Ilorin, Nigeria.

African Health Sciences Vol 12 No 3 September 2012 


\section{Methods}

\section{Study design}

The study was a prospective study carried out at University of Ilorin Teaching Hospital, Nigeria among consecutive consenting patients with chronic suppurative otitis media of more than twelve weeks attending the Ear Nose and Throat clinic after obtaining approval from ethical committee of University of Ilorin Teaching Hospital. Each patient was seen in an examination room with the parent or caregiver in attendance to enhance confidentiality.

\section{Study population}

Exclusion criteria were patients with cleft palate, patients on systemic and topical antibiotic treatment of CSOM, patients on follow up in the clinic, patients with acute suppurative otitis media and patient or parent or caregiver who does not give his or her consent, while the inclusion criteria were all patients presenting to the clinic for the first time with chronic ear discharge. All consenting patients or parents and each ear was considered as a separate entity. The patients were recruited over a period of 7 months. A total of 150 patients were recruited for the study however only 134 patients completed their questionnaire for analysis which gave a response rate of $89.3 \%$. Structured questionnaire was administered on these patients and parents or guardian that contains the biodata, the duration of symptoms, examination findings and microbiologic investigation. The parents of the children responded on their behalf while the adult responded to the questionnaire on their own.

The instruments used for the study were structured questionnaire, clinical examination, and laboratory investigation. Using a head mirror with the bright light source and battery powered keeler auroscope to view the external auditory canal and the tympanic membrane, the external ear was cleaned with $60 \%$ alcohol and $0.1-0.5 \mathrm{ml}$ of middle ear aspirate was taken $\mathrm{n}$ using ACCU-P fixed and variable volume automated micropipette. The aspirate was introduced into a bijou bottle containing sterile stuart transport medium, in which aspirates were transported to the kept in a bottle containing sterile stuart transport medium in which aspirates were transported to the microbiology laboratory for microscopy, culture and sensitivity tests. All specimen collected were subjected to gram stain. By means of a sterilized forceps, the swab stick was picked from the transport medium. This was inoculated on blood, chocolate and MacConkey agar plates.
Sterilized inoculated wire loop was then used to streak the smear.. The plates of Blood and Mac-

Conkey were placed in an aerobic incubator while the chocolate plate was incubated in a carbon-dioxide enriched atmosphere for 18-24hours after which the plates were read and isolates identified according to standard methods ${ }^{15}$

Antibiotic sensitivity testing was performed using modified Kirby Bauer disc diffusion method $_{16}$ Pure colonies of isolates were suspended in sterile normal saline inside bijou bottles and the turbidity of suspension adjusted to $0.5 \mathrm{McF}$ arland's standard. A sterile cotton swab was dipped into the suspension and squeezed against the side of the bottle, and then used to inoculate a Mueller Hinton agar before the application of single antibiotic discs and subsequently incubated at $37^{\circ} \mathrm{C}$ aerobically for $18-24 \mathrm{hrs}$.

Zone diameters of inhibition around each disc were measured using a calibrated ruler and interpreted according to Clinical and Laboratory Standard Institute (CLSI) guideline(15). Staphylococcus aureus (ATCC 25922), Escherichia coli (ATCC 25922), , and Pseudomonas aeruginosa (ATCC2785) were used as controls for gram positive, gram negative, and Pseudomonas aeruginosa isolates respectively. Antibiotic discs used were Amoxicillin-Clavulanic acid $(10 \mu)$, Azithromycin $(5 \mu), \quad$ Cefruoxime $(30 \mu)$,

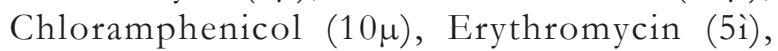
Ciprofloxacin $(5 \mu)$, Gentamicin $(30 \mu)$,Sprafloxacin $(5 \mu)$.

\section{Data analysis}

The data obtained were analyzed using statistical package for social sciences (SPSS) version 11.0 for window. $\mathrm{P}<0.05$ was taken as significant and results presented in tables and figures.

\section{Ethical considerations}

The study was at no cost to the patients and those who do not consent to participate in the study were also treated and their non-consenting did not in any way affected the treatment they received. Confidentiality is also maintained. The study was fully sponsored by the authors. Each ear was considered as a separate entity.

\section{Results}

A total of 134 patients with chronic suppurative otitis media were interviewed aged 5-64years.

The mean age of patients with chronic suppurative otitis media was 17.0 (S.D. $=15.1 \pm 1.30$ ). About $55.2 \%$ of the respondents were aged under $10 \mathrm{yrs}$ as 
shown above. Seventy-two (53.7\%) of the respondents with chronic suppurative otitis media were males giving a male to female ratio $\mathrm{M}: \mathrm{F}=1.2: 1$. The Gram stain pattern of bacterial isolate from middle ear of patients with chronic suppurative otitis media (CSOM) showed that Gram negative constitute $71.6 \%$ while Gram positive is about $27.6 \%$ and about $0.7 \%$ were contaminants containing fungal and Gram negative agents. Majority of the bacterial isolated from the middle ear of patient with CSOM were Pseudomonas aeruginosa and Klebsiella Spp in $31.3 \%$ and $23.9 \%$, the least were Streptococcus spp, E.coli and fungal contaminants (table 1).
Table 1: Pattern of bacterial isolate from middle ear of patients with chronic suppurative otitis media (CSOM)

\begin{tabular}{lc}
\hline Bacterial organisms & Frequency (\%) \\
\hline Pseudomonas aeruginosa & $42(31.3)$ \\
Klebsiella spp & $32(23.9)$ \\
Staphylococcus spp & $22(16.4)$ \\
Proteus mirabilis & $20(14.9)$ \\
Streptococcus spp & $15(11.2)$ \\
Escherichia coli & $06(4.5)$ \\
Fungal/Pseudomonas spp & $01(0.7)$ \\
\hline
\end{tabular}

The isolates were confirmed on gram staining.

Almost all the bacterial organisms in the middle ear were sensitive to ciprofloxacin except Proteus mirabilis. The highest sensitivity pattern was recorded among the Pseudomonas aeruginosa, and then streptococcus faecalis. Gentamicin was also found to also be an effective antibacterial agent to Streptococcus faecalis.

Ciprofloxacin, azithromycin and amoxicillinclavulanic acid were found to be effective against Pseudomonas aeruginosa

Table 2: Sensitivity pattern of middle ear bacteria isolates in patients with CSOM

\begin{tabular}{|c|c|c|c|c|c|c|}
\hline Organisms & $\begin{array}{l}\text { Streptococcus } \\
\text { faecalis } N=15\end{array}$ & $\begin{array}{l}\text { Staphylococcus } \\
\text { aureus } \mathrm{N}=22\end{array}$ & $\begin{array}{l}\text { Klebsiellapneu } \\
\text { moniae } \mathrm{N}=32\end{array}$ & 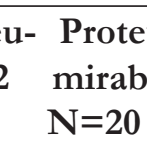 & $\begin{array}{l}\text { us Pseudomonas } \\
\text { ilis aeruginosa } \\
\mathrm{N}=42\end{array}$ & $\begin{array}{l}\text { Escherichia } \\
\text { coli } N=6\end{array}$ \\
\hline Antibiotics & & & & & & \\
\hline $\mathrm{AC}$ & $4(26.7 \%)$ & $6(27 \%)$ & $14(44 \%)$ & $3(15 \%)$ & $29(69 \%)$ & $3(50 \%)$ \\
\hline AT & $8(53 \%)$ & $11(50 \%)$ & - & - & - & - \\
\hline $\mathrm{CU}$ & $7(47 \%)$ & $13(59 \%)$ & $17(53 \%)$ & $8(40 \%)$ & $25(60 \%)$ & $2(33.3 \%)$ \\
\hline C & $2(13 \%)$ & $7(32 \%)$ & $14(44 \%)$ & $11(55 \%)$ & $20(48 \%)$ & $4(66.6 \%)$ \\
\hline $\mathrm{E}$ & $3(20 \%)$ & $9(41 \%)$ & - & - & - & - \\
\hline $\mathrm{CF}$ & $13(87 \%)$ & $15(68 \%)$ & $21(66 \%)$ & $10(50 \%)$ & $37(88 \%)$ & $4(66.6 \%)$ \\
\hline G & $9(60 \%)$ & $13(59 \%)$ & $11(34 \%)$ & $11(55 \%)$ & $19(45 \%)$ & $3(50 \%)$ \\
\hline SF & $8(53 \%)$ & $12(55 \%)$ & $18(56 \%)$ & $10(50 \%)$ & $25(60 \%)$ & $2(33.3 \%)$ \\
\hline
\end{tabular}

AC-Amoxycillin-Clavulanic acid, AT-Azithromycin CU-Cefuroxime Sodium, C- Chloramphenicol, EErythromycin CF- Ciprofloxacin, G- Gentamicin, SF- Sparfloxacin

\section{Discussion}

Otitis media is a serious healthcare concern worldwide, not only because of the distress it causes the patient and their family but also because of the substantial economic burden it imposes on the health care system. Previous publications have reported its incidence to depend on race and socio- economic factors ${ }^{18}$. A high prevalence has been reported among the Eskimos, American Indians, Australian aboriginal children and among black South Africans18. Poor living conditions, overcrowding, poor hygiene and nutrition have been suggested as a basis for the widespread prevalence of CSOM in developing countries 18. A high occurence of the disease among the paediatric age group which constituted more than $50 \%$ of the participants was also reported in the study. It is found to be commoner among the males more than females as the ratio was found to be 1.2 :1.0 similar to other report 1 and at variance with a study done in the same region, although this is a

African Health Sciences Vol 12 No 3 September 2012 
hospital based study while the other was a community based ${ }^{18}$. This may be a reflection of the overall male predominance of childhood infections due to anatomic, behavioural, and socioeconomic differences between males and females ${ }^{19}$. The most prevalent organism was a gram negative organism which is about thrice the gram positive agent from the middle ear aspirate and these organisms, when correlated with the sex, were found to be commoner in males than females. The gram negative agents implicated in the study were Pseudomonas aeruginosa and Klebsiella in $31.3 \%$ and $23.9 \%$ respectively. This was followed by Staphylococcus aureus in 16.4\% and the least was a fungal contaminant in $0.1 \%$ but Staph. aureus may be considered to be a contaminant from the external auditory canal (EAC) ${ }^{18}$. However, the role of this organism as a potential causative agent in middle ear infection could not be excluded ${ }^{18}$ because the specimen was obtained using the aspiration technique. The pattern of bacterial isolates showed that Pseudomonas aeruginosa was the most prevalent bacterial organism found in the middle ear of the respondents with chronic suppurative otitis media which is similar to findings elsewhere ${ }^{10,18,21}$. This is followed by Klebsiella spp. as the second commonest while in some other centres such as Ibadan and Jos Nigeria found Staphylococcus aureus was found to be the second commonest ${ }^{9,10}$. Our finding was also at variance with a study done in Kaduna which revealed Klebsiella spp as the commonest bacterial organism ${ }^{22}$. Proteus spp was less prevalent $(14.9 \%)$ based on findings from the middle ear culture of the respondents as against some other study where it was found to be the commonest in Egypt and second commonest in other studies in Ibadan ${ }^{9}, 21,23$. However, other investigators found that the most common organism was Staph. aureus ${ }^{24,25}$. In other studies, $S$. aureus and Proteus spp. were the predominant pathogens of CSOM26. The presence of a mixed isolate is not unexpected which by proportion is insignificant similar to other finding elsewhere ${ }^{10,18,26}$. Invitro testing on the plate revealed that most organisms were highly sensitive to ciprofloxacin. It is a commonly used fluoroquinolones as reported in a multi-center study on chronic suppurative otitis media ${ }^{27}$ Amoxicillinclavulanic acid and cefuroxime were found to be effective against organisms in the middle ear with CSOM. This is at variance with a study done in southern part of Nigeria which identified Pseudomonas aeruginosa as the predominant isolate showing high susceptibility profile to ceftazidime, ceftriaxone and gentamicin28. The increased susceptibility to quinolones is similar to findings by Lilly-Tariah ${ }^{29}$.

Ciprofloxacin was shown to be the most effective, with high sensitivities for the most commonly isolated organisms. Several reports have indicated its efficacy particularly against Pseudomonas aeruginosa and

Staphylococcus aureus ${ }^{30}$. They would hence, provide a viable option for the treatment of patients with active CSOM; as it is available in oral, injectables and topical ear drops as well ${ }^{31}$. The most important adverse effect of systemic ciprofloxacin reported is arthropathy and cartilage damage noticed in weight bearing joints of some juvenile animals species such as mice, dogs, rats, rabbits, and in-vitro human cell culture which wasfeared to be extrapolated to children $^{32,33}$. However recent Cochrane database study on quinolones, safety of ciprofloxacin use in children and concluded that appears to be safe and well tolerated ${ }^{33,34}$. Thus ciprofloxacin can serve as a first line treatment in contrast to Oni et $\mathrm{al}^{9}$ who recommended penicillin as first line drugs treatment and quinolone as second line. Previous workers have found gentamicin as the most sensitive agent ${ }^{10,30}$.

\section{Conclusion}

Chronic otitis media is still a childhood problem among the under tens: It is more prevalent among males than the females, the commonest agents implicated being Pseudomonas aeruginosa, followed by klebsiella organisms. Ciprofloxacin, azithromycin and amoxicillin-clavulanic acid were found to be most effective antibiotic agent against Pseudomonas aeruginosa.

\section{Acknowledgement}

The authors want to acknowledge the patients who consented to this study and the staff of Microbiology department who helped in the study.

\section{Conflict of interest}

Authors declare that they have no conflict of interest and all sources of support for the research was self sponsored. There is no association with any product or subject that may constitute conflict of interest.

\section{References}


1. El-Gendy GD. The incidence of otitis media with effusion in Menoufiya school children. MD Thesis, Faculty of Medicine, Menoufiya University 1998.

2. St Sauver J, Marrs CF, Foxman B, Somsel P, Madera R, Gilsdorf JR. Risk factors for otitis media and carriage of multiple strains of Haemophilus influenzae and streptococcus pneumoniae. Emerg Infect Dis 2000;6 (6):622 30.

3. Leach AJ, Morris PS. Antibiotics for the prevention of acute and chronic suppurative otitis media in children. Cochrane Database Syst Rev 2006;18 (4): CD004401.

4. Tahira M, Mohammed A M, Gulnaz K, Mustafa K. Pseudomonas aeruginosa in chronic suppurative otitis media: Sensitivity spectrum against various antibiotics in Karachi.J Ayub Med Coll Abbottabad 2009;21(2):120-123

5. Berman S. Otitis media in children. NEngJ Med. 1995;332 (23): 1560-1565.

6. Yeo SG, Park DC, Hong SM, Cha CI, Kim MG. Bacteriology of chronic suppurative otitis media-a multicentre study. Acta Otolaryngol 2007; 127:1062- 67 .

7. Ibekwe AO. Chronic suppurative otitis media in Nigerian children. J. Paediatrics. 1985; 12:17-19.

8. Lasisi AO, Olaniyan FA, Muibi SA, Azeez IA, Abdulwasiu KG, Lasisi TJ, et al. Clinical and demographic risk factors associated with chronic suppurative otitis media. Int $J$ Pediatr Otorbinolaryngol 2007;71(10):1549-54.

9. Oni AA, Bakare RA, Nwaorgu OGB, Ogunkunle $\mathrm{MO}$, Toki RA, Bacterial agents of discharging ears and antimicrobial sensitivity pattern in children in Ibadan, Nigeria. WAJM, 2001;20(2) :131 -135.

10. Brook I, Frazier E. Microbial dynamics of persistent purulent otitis media in children. $J$. Pediatrics, 1996; 128: 237-240

11. John AF. Chronic otitis media: diagnosis and treatment. Med Clin North America 1991; 75: 1277 1291.

12. Hatcher J, Smith A, Mackenzie I. A prevalence study of ear problem in school children in Kiambi district, Kenya. Int. J. Paediatr. Otorbinolaryngol. 1995; 33: 197-201

13. Acuin J, Chronic suppurative otitis media, burden of illness and management options. World Health Organization, Geneva, Switzerland 2004; $1: 17$
14. Anthony Wright, Anatomy and ultrastructure of the human ear, Scott-Brown's otolaryngology, Basic science sixth edition; Booth JBand Kerr AG,(eds) London, Butterworth-Heinemann 1997:1/1/7-1/1/26.

15.Cheesbrough M (2000). Medical Laboratory Manual for Tropical Countries. Vol. 11. Cambridge University press

16. Bauer AW, Kirby QMM, Sherrens JC, Turik M. Antibiotic susceptibility testing by standardized single disk method. A M J Clin. Path. 1966; 45: 493-302.

17. Performance Standard for Antimicrobial Disk Susceptibility Test, CLSI 2006; 26(1).

18. Ologe FE, Nwawolo CC. Prevalence of chronic suppurative otitis media (CSOM) among school children in a rural community in Nigeria. Nig. Postgrad. Med J. 2002; 9:63- 66.

19. Falagas ME, Mourtzoukou EG, Vardakas KZ. Sex differences in the incidence and severity of respiratory tract infections. Respir Med 2007;101(9):1845- 63.

20. Cheng SF, Casselbrant ML, Yellon RF, Bluestone CD. Bacteriology of otorhea in children. In: Lim DJ, Bluestone CD, Casselbrant M Klein JO, Ogra PL, editors. Recent Advances of Otitis Media. BC Deker Inc; 1996: 312-14.

21. Bluestone C D. Pathogenesis and Epidemiology of chronic otitis media, WHO/CIBA foundation workshop, report on prevention of hearing impairment for chronic otitis media held at CIBA foundation, London 1996; 14-17

22. A A Bakari, A A. Adoga, O A. Afolabi, A M. Kodiya, B M. Ahmad, Pattern of Chronic suppurative otitis media at the National Ear Care Center, Kaduna, Nigeria. Journal of Medicine in the Tropics 2010; $12: 22-25$

23. Brobby GW, Zadik P. Bacteriology of otitis media in Ghana. Tropical Doctor, 1987; 17:9192.

24. Oyeka CA, Oyeka IC, Okeke GN. Prevalence of bacterial otitis media in primary school children in Enugu Surburb, Enugu State, Nigeria. West Africa J Med1995;14(2):78-81.

25. Brook I, Santosa G. Microbiology of chronic suppurative otitis media in children in Surabaya, Indonesia. Int $J$ Pediatr Otorhinolaryngol 1995;31(1):23-8.

26. Abera B, Biadeglegne F. Antimicrobial resistance patterns of Staphylococcus aureus and Proteus spp. isolated from otitis media at Bahir Dar 
Regional Laboratory, North West Ethiopia. Ethiop Med J 2009;47(4):271 -6.

27. Miró N, Controlled multicenter study on chronic suppurative otitis media treated with topical applications of ciprofloxacin $0.2 \%$ solution in single-dose containers or combination of polymyxin B, neomycin, and hydrocortisone suspension. Otolaryngol Head Neck Surg. 2000; 123(5):617-23

28. Wariso BA, Ibe SN Bacteriology of chronic discharging ears in Port Harcourt, Nigeria West Afr J ed. 2006; 25(3):219-22.

29. Da Lilly-Tariah OB, Assesment for modalities for treatment of otorrhea in active phase of simple chronic suppurative otitis media in Jos University Teaching Hospital. Nigerian Journal of Otorbinolaryngology 2005 ;2(1): 22-26

30. Ibekwe AO, Al shareef $\mathrm{Z}$, Benayam A. Anaerobes and Fungi in chronic suppurative otitis media. Ann. Otol Rhinol Laryngol 1997;106(8): 649-652.
31. Aslam MA, Ahmed Z, Azim R Microbiology and drug sensitivity patterns of chronic suppurative otitis media. J Coll Physicians Surg Pak. 2004; 14(8):459-61.

32. Linseman DA, Hampton LA, Branstetter DG. Quinolone-induced athropathy in the neonatal mouse: Morphological analysis of articular lesions produced by pipemidic acid and ciprofloxacin. Fundam Appl Toxicol 1995; 28:5964

33. Rebecca Mitchell, Noel Cranswick. What is the evidence of safety of quinolone use in children? International Child Health Review Collaboration www.ichrc.org. September 2008 ;1-4

34. Grady R. systemic quinolone antibiotics in children: a review of the use and safety. Expert Opin Drug Saf. 2005; 4(4): 62330 